\title{
Un viajero medieval. Benjamín de Tudela
}

\section{León Levy}

A través de los medios de comunicación conocemos con frecuencia crónicas de viajes a diferentes lugares, mas poco sabemos sobre viajes realizados en época pretérita, en tiempos en que se carecía de aviones, buques veloces, automóviles, el hecho de viajar ya tenía un poco de epopeya, están más difundidos los viajes de Marco Polo y los Descubridores pero otros se ignoran, es mi propósito con este trabajo ofrecer al lector unas notas sobre el viaje de un español del medievo Benjamín (en hebreo Benyamin) hijo de Yoná, conocido como Benjamín de Tudela.

Nacido en la Navarra ciudad de Tudela, en aquel entonces adscrita a la circunscripción de Zaragoza, fue hombre cultivado, estudioso y amante del saber, se le atribuye la categoría religiosa de Rabi (Rebbi) fundamentado en que aparece la $R$. antepuesta a su nombre, ello no implica necesariamente tal categoría ya que a veces se aplica al término como muestra de cortesía, en la actualidad cuando un judío accede a ciertas ceremonias religiosas o en caso de fallecimiento se rezan plegarias por su alma, se le denomina Rebbi.

Ello no excluye que dada su situación social y la importancia de la "aljama" tudelana hubiera estudiado las Sagradas Escrituras y Teología, lo que si es más confirmado su calidad de políglota, calidad muy necesaria para viajar.

Surgen teorías en torno al origen del viaje, se atribuye a su condición de comerciante en joyas y piedras preciosas tuviera necesidad de buscar artículos de novedad, pero es necesario admitir la existencia de un espiritu un tanto aventurero e inquieto y el deseo de aprender, sin duda a causa de su "identidad judía" deseaba conocer la suerte de los judíos en diferentes países y así lo muestran los datos tan exactos que da sobre multiples comunidades judías, señalando número y circunstancias.

Advirtamos que más que un libro de construcción literaria es un cúmulo de observaciones, lo que hoy llamariamos reportaje, sin pensar en la belleza del estilo, en el que relata lo que vivió y a la vez recoge noticias adquiridas de segunda mano, no está determinado completamente el contenido del itinerario pues consultados dos de los mapas más conocidos el de Martín Gilbert y Haim Beinart no coinciden plenamente.

Partiendo de su ciudad natal sale de Gerona y su primer paso es Francia (La Provenza), más tarde seguiría a Marsella, luego Italia, Grecia, Isla de Chipre, islas de Egeo, Turquía, Libano, Tierra Santa, Damasco, Irán, Mesopotamia, Egipto desde donde emprende el regreso, no se conoce exactamente la duración de este viaje, se barajan cifras de 5, 10 y 14 años. Se calcula nació entre los afios 1130 a 1132 y falleció en 1175 pocos años después de su retorno.

Este interesante libro pronto alcanzó difusión, y tenemos una primera edición en 
Turquía, a continuación muchas más, en Friburgo, Leiden, Amsterdam, Berlin, Jerusalem, Bagdad y su traducción a numerosos idiomas.

El insigne erudito español Benito Arias Montano (cuyo nombre lleva el Instituto de Estudios Judíos del Consejo de Investigaciones Científicas), realizó a finales del siglo XVI una traducción al latín.

La traducción a lengua castellana la realiza el notable experto en temas semíticos Dr. González Llubera, que por cierto sitúa el viaje del 1160 a 1173.

En nuestros días el erudito José R. Magdalena y Nom de Deu, ha conseguido una versión castellana de indudable valía, con una aportación de datos, unos documentados comentarios y un buen listado bibliográfico, lo que implica una valiosa contribución al estudio y divulgación de este viaje.

En su recorrido tuvo ocasión de conocer a grandes luminarias de la religión judía amén de otras personalidades, uno de los primeros contactos lo tuvo con Rebbi Yudah Ben Tibbón, poliglota, médico y teólogo refugiado en la ciudad francesa de Lunes, donde encontró asilo huyendo de las persecuciones de los almohades.

Sobre este viaje seffalaremos algunos comentarios de interés, observaciones y hechos curiosos, Absteniéndonos de señalar distancias entre las localidades y número de judíos en cada lugar, que haría muy extenso este trabajo.

Comienza a hablarnos de Narbona (Francia) donde existen numerosos sabios judíos bajo la presidencia del Rabino Calónimas descendiente del Rey David, esta comunidad disfrutaba de riquezas y tierras que por un privilegio especial nadie podía expropiar.

Nos relata en Génova las casas poseen torres, las que se usan para fines bélicos en caso de divergencias entre los ciudadanos, igualmente en Pisa halla estas torres que llegan a alcanzar la cifra de 10.000. En Roma alude al Papa Alejandro III al que llama "Obispo Mayor de los cristianos", el cual cuenta con servidores judíos, algunos de ellos con puestos relevantes. En esta ciudad circula una leyenda entre los judíos relativa a unas columnas existentes en la Iglesia de San Juan de Letrán, procedentes del Templo de Salomón, las cuales el día 9 de Ab (aniversario de la destrucción del Templo) exhalan un líquido acuoso.

Dentro de su deambular, cuenta la existencia de unos seres llamados valacos residentes en los Montes de Valaquia (hoy Rumanía), que descienden al llano para asolar y robar las ciudades griegas, se trata de gentes indómitas, nadie puede guerrear contra ellos y no tienen Rey que les mande, a los judíos les llaman "hermanos" pero ello no es óbice para que les expolien.

Sobre Costantinopla escribe que no hay ciudad que la iguale, a excepción de Damasco, con un Papa de los griegos que gobierna sobre "tantas iglesias como días tiene el años", los judíos habitantes de la Ciudad no pueden salir de ella por vía terrestre y tienen que hacerlo por el mar, teniendo prohibido el ir en caballo estando exceptuado de esta prohibición solamente un judío egipcio que es el Médico Real.

En Antioquía existe un gran manantial de agua ubicado en la montaña, a través de conductos subterráneos es conducida el agua a los domicilios de los notables de la ciudad.

En su visita al Líbano al ocuparse de Sidón y Monte Hermón habla de sus habitantes llamados drusos, gente depravada ya que los hombres cohabitan con sus hijas y los 
hermanos con las hermanas.

Entra a Tierra Santa por Acco (San Juan de Acre), sigue a Ha-Jefer (Haifa), visita las tumbas del sacrosante Eliyau Hanabi (el Profeta) y de José hijo de Jacob, describe las costumbres de los judíos samaritanos y por fin llega a Jerusalem.

Escribe que la Ciudad Santa es una pequeffa plaza fortificada, donde existen gentes de todos los países y se oyen todas las lenguas, los judíos tienen un acuerdo con las Autoridades para disfrutar del monopolio de la tintorería.

Conoce la Iglesia del Sepulcro, donde está enterrado el "Hombre" (se refiere a Jesús), nos habla de las cuatro puertas que entonces tenía la ciudad, relata que en el "Muro" (el Kotel Maarabi) van a rezar los judíos (costumbre todavía existente), las gentes beben aguas de lluvia recogidas en algibes, afiade que desde el Mar Muerto se puede contemplar la estatua de la mujer de Lot convertida en sal.

Participamos de una fantástica leyenda en torno a la tumba del Rey David, situada en un palacio de oro, plata y mármol, que fue cubierta por las tierras debemos aclarar que en la actualidad se discute la autenticidad del emplazamiento de tal tumba.

Igualmente visita Bet Lehem (Belén) y la tumba de la Madre Raquel, a continuación la "Meará Majpelá", cueva donde están los sepulcros de Abraham, Isaac, Jacob y esposas, sobre ella cuenta asimismo una leyenda sobre la ubicación real de tales tumbas dentro de la cueva.

Tras recorrer ampliamente todo el territorio actualmente integrado en el Estado de Israel, emprende viaje a Damasco.

Queda maravillado de dicha ciudad, especialmente de su Gran Mezquita que posee un muro de cristal, hecha por obra de encantamiento, grandes columnas de oro y cristal, en ella está la costilla del gigante Rey Abramaz, de palmos de longitud por 2 palmos de ancho (ignoramos que se consideraba la medida del palmo, pero es de suponer que como ahora y por tanto se calcula en $20 \mathrm{~cm}$.).

Tras recorrer las riberas del Tigris tiene la gran ocasión de conocer Ninive, la ciudad bíblica que dio lugar a la hazaña de Yoná (Jonás) y el pez Leviatán.

Visita Bagdad gobernada por el Califa Comendador de los Creyentes El Abassi, descendiente de Mahoma, al que considera como el Papa de los islailitas, nos refiere como este monarca trata muy bien a los judíos, hay unos 40.000 , y es persona de costumbres muy honestas pues se dedica a confeccionar alfombras que sus dignatarios se encargan de vender y con el importe atiende a su subsistencia.

Curiosamente este hombre de tan morigeradas costumbres tiene a sus hermanos y familiares directos en hermosos palacios, gozan de riquezas y bienestar mas no pueden salir de ellos, están en calidad de presos, así evita la posibilidad de una sublevación contra la persona del Califa.

Prosigue en andadura y llega a Babel, donde se hallan las ruinas del Palacio de Nabucodonosor, indicando que los habitantes del lugar no pueden entrar a él ante la profusión de reptiles, alacranes y otras especies dañinas. Cerca de este palacio se halla el horno donde nos cuenta el libro de Daniel fueron arrojados tres venerables judios (Hananiá, Mijael y Azariá).

Arriba a la ciudad Teima lugar de residencia de tribus judias muy belicosas, dedicadas al saqueo y pillaje, que tienen su propio Príncipe y no admiten el yugo extranjero. 
Tiene ocasión de conocer Susán, la capilal del reino del Rey Asuero, al que alude la "Meguila" de la Reina Esther, sobre la destrucción del pueblo, y que ha motivado la actual festividad hebrea del Purim, al haber quedado sin efecto tal amenaza.

Visita la tumba del profeta Daniel, que según los habitantes de la región trae la suerte al lugar y los campos son benditos convertiéndose en verdaderos y ubérrimos vergeles, lo que motivó guerras civiles para disputarse la propiedad del terreno.

Tras un largo periplo arriba por vía marítima a Cush (este nombre es el que se da en los viejos judíos a Etiopía, se ignora si eran los actuales límites o se extendia a tierras hoy egipcias), país que denomina Adoradores del Sol, gente muy inclinada a la astrología, de piel negra, gente honesta y seria en sus negocios, cuyo Gobierno coloca bajo su protección los bienes de los visitantes para cubrirlos contra robos o expoliaciones, es una tierra tan calurosa que durante 6 meses del año la gente permanece en sus hogares durante el día y la vida se desarrolla durante la noche, se colocan grandes antorchas para asegurar el alumbrado.

Mas adelante nos brinda noticias sobre China, India y Ceilán, examinando su contenido es totalmente opuesto al modo de describir los lugares visitados, por lo que supone es transcripción de relatos oídos.

Por fin llega a El Cairo, gran ciudad donde residen unos 7.000 judíos, que se hallan divididos en dos grandes grupos "Israel" y "Babel", tienen ritos litúrgicos distintos, los babilonios recitan la Torá según el sistema de los judíos sefardíes, pero ambos grupos se reúnen para celebrar de forma conjunta las festividades de Simhá Torá (Fiesta de la Ley) y Sabuot (Pentecostés).

Manifiesta que la ciudad está compuesta de dos partes Cairo Nuevo y Cairo Viejo (llamado Fustat), que abundan los mercados y zocos, lugar donde nunca cae lluvia ni hielo, jamás conocieron la nieve, gracias a la subida de las aguas del río Nilo, que dura unos 2 meses, las tierras quedan irrigadas y abonadas, diariamente se comunica al pueblo la medida del nivel de las aguas, describiendo la forma curiosa en que es determinada.

Se desplaza a Alejandría, lugar de residencia de la Academia de Aristóteles, que es frecuentada por gentes del orbe entero, la ciudad está cruzada por una serie de puentes y cuenta con un gran Faro que sirve desde larga distancia como orientación de los navegantes y fue considerado como una de las maravillas del mundo, continuamente se están encendiendo antorchas para asegurar la luz, esta ciudad contaba con un gran espejo que permitía detectar la presencia de buques extranjeros y tomar las debidas precauciones pero un marinero griego, con un ingenioso ardid, lo destruyó y ello permitió la llegada de los cristianos y otros pueblos.

A través del relato se deduce que por vía marítima inicia el regreso y se dirige a Mesina desde donde continúa a Palermo, recorre Italia de Sur a Norte, leemos descripciones sobre Alemania, Bohemia y Praga, pero en un estilo conciso que choca con lo prólijo de su modo de describir, ello induce se trata, nuevamente de reproducir relatos oídos, se sabe estuvo en Francia desde donde retorna a Espafia.

Damos fin a estos comentarios en torno al Libro de Viajes de Benjamín de Tudela, que tienen un carácter meramente informativo para hacer llegar al lector un ligero sumario del periplo, que contiene un marcado interés y detalles bien curiosos, que les pudiera inducir a su lectura. 